\title{
A west-dipping seismogenic boundary beneath the Chia-Yi area of western Taiwan
}

\author{
Min-Hung Shih ${ }^{1,2}$, Cheng-Horng Lin ${ }^{1,2,3,4, *}$, Hsin-Chieh Pu ${ }^{5}$, Ya-Chuan Lai ${ }^{1,2}$, and Hsiao-Fen Lee ${ }^{1,2}$ \\ ${ }^{\prime}$ Institute of Earth Sciences, Academia Sinica, Taipei City, Taiwan \\ ${ }^{2}$ Taiwan Volcano Observatory at Tatun, Taipei City, Taiwan \\ ${ }^{3}$ Department of Geosciences, National Taiwan University, Taipei City, Taiwan \\ ${ }^{4}$ National Center for Research on Earthquake Engineering, National Applied Research Laboratories, Taipei City, Taiwan \\ ${ }^{5}$ Central Weather Bureau, Taipei City, Taiwan
}

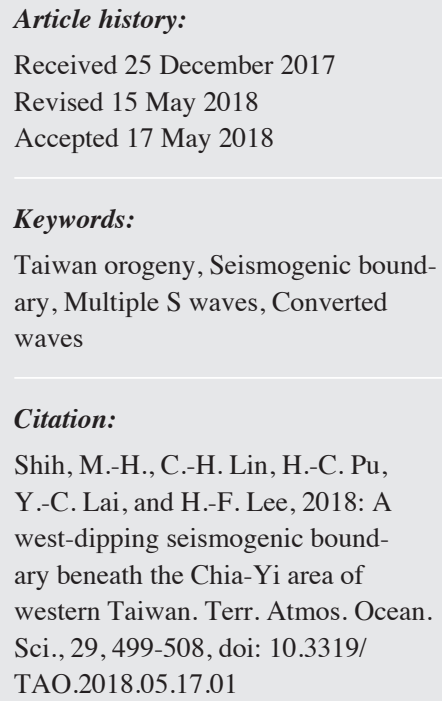

\begin{abstract}
Taiwan is one of the most typical arc-continental collision systems in the world. The Taiwan orogeny is often explained by the thin-skin model, where a shallow decollement, with depths of less than $10 \mathrm{~km}$, is considered as the crustal deformation boundary for generating significant mountains on the island of Taiwan. In this study, the seismic data generated by crustal earthquakes, recorded by seismic stations in the Chia-Yi area of western Taiwan was examined to find the crustal structures beneath the Taiwan orogeny. A significant velocity boundary below the decollement was found from unambiguous multiple secondary waves and phases of primary waves converted to secondary waves. Careful comparison between the observations and calculated results of the travel-time and ray-path indicates that this boundary is dipping to the west at $\sim 10$ degrees, which, surprisingly, is dipping to the opposite direction of the proposed decollement. It is also interesting to note that this boundary is not only a velocity boundary but also consistent with a seismicity boundary. This westdipping boundary is the major seismogenic boundary in the upper crust, while the east-dipping decollement proposed earlier is a geological boundary. As a result, the westward dipping boundary observed in this study is more suitable, than the eastward dipping decollement, to be the seismogenic boundary in the Chia-Yi area.
\end{abstract}

\section{INTRODUCTION}

The Taiwan orogeny is often considered one of the most typical arc-continental collision systems in the world (Suppe 1981; Lin 2000, 2002; Malavieille et al. 2002; Malavieille and Trullenque 2009; Byrne et al.2011). The continental margin of the Eurasian plate collided with the Luzon volcanic arc of the Philippine Sea plate (Fig. 1), which may act as a strong indenter, or backstop, forcing the convergent rocks to deform and create significant mountains on the island of Taiwan (Suppe 1980). In the "thin-skin" tectonic model (Suppe 1980), the strong crustal deformation was thought to be limited to the shallow sedimentary rocks above the decollement, a boundary, dipping at less than 10 degrees towards the east, in the upper crust. Its depth roughly increases from $\sim 5 \mathrm{~km}$ beneath the Coastal Plain in west-

\footnotetext{
* Corresponding author

E-mail:lin@earth.sinica.edu.tw
}

ern Taiwan to $\sim 10 \mathrm{~km}$ beneath the Central Range (Fig. 1). Thus, it seems that the existence of the decollement plays an important role in the generation of mountains on the island of Taiwan.

Based on the seismicity recorded on the island of Taiwan in the past decades (Wu et al. 2008), however, most of the earthquakes at the Coastal Plain are located below the decollement (Fig. 2). Since earthquakes within the crust might directly reflect some kind of crustal deformation, the earthquakes clustered below the decollement may indicate some crustal deformation occurring around the mid-crust. Typically, some larger earthquakes often occurred at depths below the decollement. For instance, the focal depth of the 1999 Chi-Chi earthquake (M 7.3) was below the decollement (Shin et al. 2000). In fact, some of blind faults dipping to the west have been reported from the detailed study of earthquake data (i.e., Wen and Chen 2004; Chen et al. 2008). All of those observations indicates that the major 

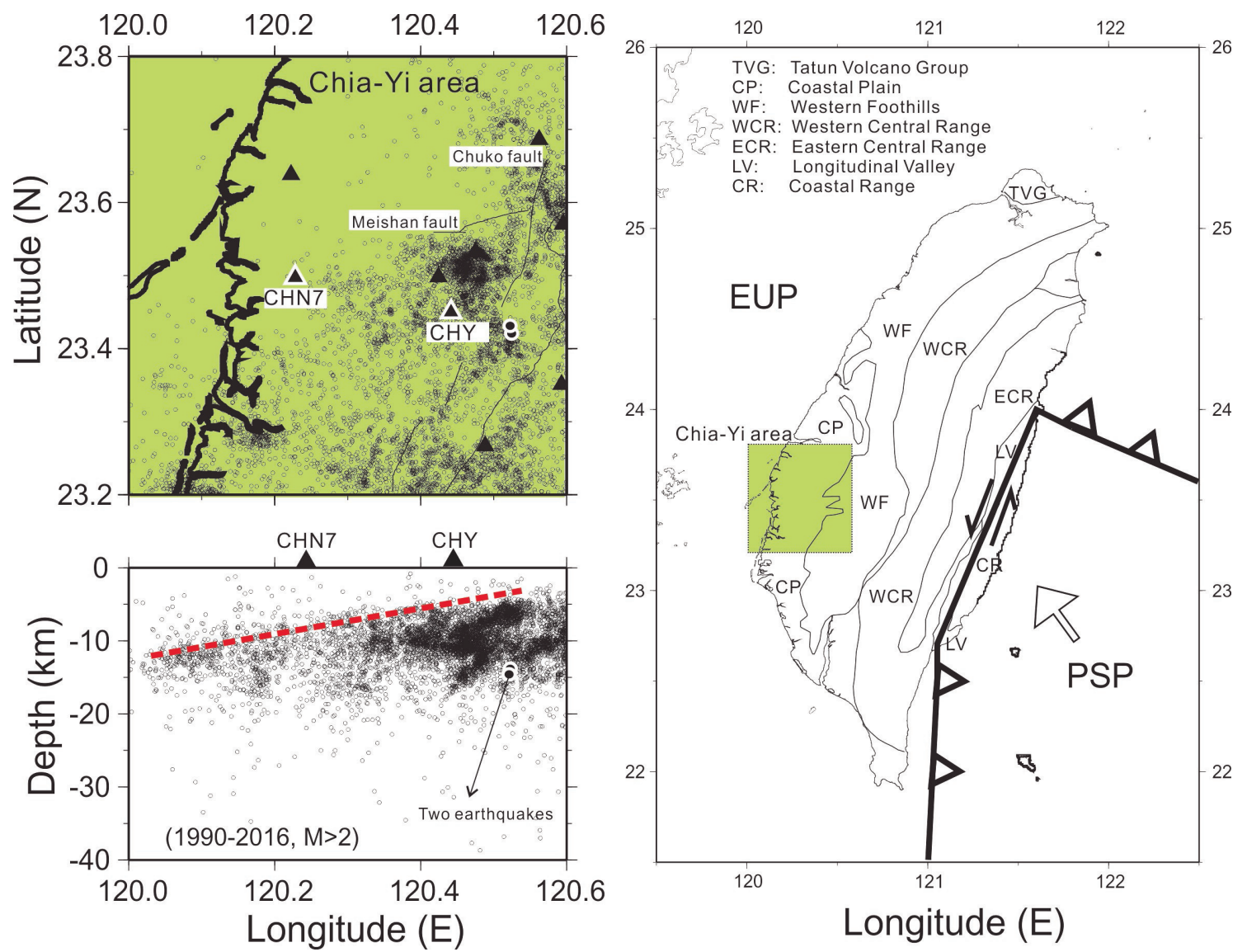

Fig. 1. Seismicity (small circles) in the Chia-Yi area, marked in green, of Taiwan and simplified tectonics in the Taiwan area. The seismic data is downloaded from the relocated earthquake catalog (Wu et al. 2008). Two seismic stations (CHN7 and CHY) and two local earthquakes are marked by triangles and black dots, respectively. The Eurasian and Philippine Sea plates are marked by EUP and PSP, respectively. The red line delineates the top of the major seismogenic layer in the upper crust.

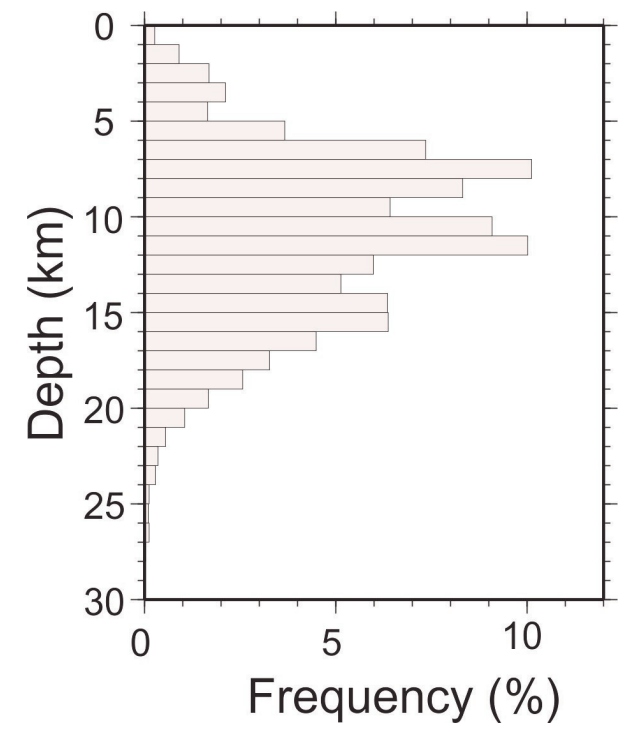

Fig. 2. Histogram of focal depths in the Chia-Yi area of western Taiwan. 
crustal deformation took place below the decollement depth in the western part of Taiwan. Thus, it is of interest to find any other major structures beneath the decollement at the Chai-Yi area of western Taiwan.

In order to examine the existence of the decollement and any other major discontinuities beneath the Coastal Plain, we carefully investigated the seismic data generated by earthquakes that occurred just beneath the Chia-Yi area, where a typical 2-D depth profile for the decollement was demonstrated (Suppe 1981). We attempted to identify the seismic waves reflected or converted on the major boundaries within the crust, which is difficult to image from traditional seismic methods. The results show several multiple-reflection secondary waves ( $\mathrm{S}$ waves). The $\mathrm{S}$ waves converted from the primary waves (P waves) were clearly identified to infer the presence of discontinuities. The observations were compared with the calculations of both a ray-tracing and a travel-time simulation with a simplified 2-D model. Finally, the major boundaries within the upper crust are discussed with respect to the seismogenic layers in the Coastal Plain of western Taiwan.

\section{GENERAL TECTONICS AND GEOLOGY}

The island of Taiwan is situated at the convergence boundary between the Eurasian plate (EUP) and the Philippine Sea plate (PSP) (Fig. 1). Significant mountain formation has taken place over several million years due to the strong convergence between these two plates (Teng 1996). The boundary between both plates on the island of Taiwan is clearly marked along the Longitudinal Valley (LV), or the suture zone. West of the LV, the major geological regions (Ho 1988) in the continental margin of the EUP, from the west to the east, include the Coastal Plain (CP), Western Foothills (WF), Western Central Ranges (WCR), and Eastern Central Range (ECR). East of the LV, the Coastal Range region is a portion of the Luzon volcanic arc on the PSP.

One of the most popular tectonic models for explaining the Taiwan orogeny is the thin-skin model (Suppe 1981), which was initially proposed according to the well-documented data such as geologic and seismic profiles at the Chai-Yi area of western Taiwan. In this model, one of the most important assumptions is to consider the existence of the decollement beneath the island of Taiwan in the shallow upper crust. The depth of the decollement gradually increases from $\sim 5$ beneath the Coastal Plain to $\sim 10 \mathrm{~km}$ beneath the Central Range. East of the Central Range, the Luzon volcanic arc of the PSP acts as the indenter, or backstop, to create significant mountains in major parts of Taiwan. Thus, both the elevation and the degree of rock metamorphosis increase eastward. These phenomena resulted from the limited crustal deformation above the decollement within the continental margin of the EUP.

Major evidence to identify the decollement was ob- tained from the seismic reflection profile and the borehole drilling results beneath the Coastal Plain of the western Taiwan area (Suppe 1980). The typical result was revealed at the Chai-Yi area in which a significant geological boundary dipping eastward was identified at depths of around $4-5 \mathrm{~km}$. The decollement was often defined as the geological boundary between the Miocene and Cretaceous rocks. A sequence of imbricate thrust belts was at the uppermost crust above the decollement, while the Cretaceous bed-rocks below the thrust belts were non-deformed. Also, a high pore-pressure fissure was observed in and around this major boundary. Thus, it was reasonable to assume that this boundary was the typical decollement beneath western Taiwan. However, it seems there is no solid evidence to prove that such a major boundary or decollement would extend eastward beneath the Western Foothills and even the Central Range.

In the past two decades, besides, some of crustal structures were conducted from the seismic data recorded in the Chia-Yi area. First of all, the detailed 3-D seismic topographic images were obtained from the dense seismic stations and abundant earthquakes in the Chia-Yi area (Wen and Chen 2004). In addition to the three-dimensional velocity (Vp) structures, the variations of $\mathrm{Vp} / \mathrm{Vs}$ ratios had been discussed for knowing the possible relationship between active faults on the surface and seismogenic zones within the crust. In particular, it is interesting to see that the results suggested the active fault was roughly identified along the boundary between high and low Vp/Vs zones. Based on the seismicity and focal mechanisms, furthermore, Chen et al. (2008) proposed a model of multiple detachment faults at the mid-crust. Also, some tear-fault and back-thrust might be involved for generated large earthquakes such as the 1999 Chia-Yi earthquake.

\section{EARTHQUAKE DATA}

In order to find other possible discontinuities beneath the western part of Taiwan, we have examined earthquakes in the Chia-Yi area where many earthquakes (Lin 2001) and active faults have been detected (Lin et al. 2008). The relocated seismicity (Wu et al. 2008) shows that many background earthquakes are clustered around Chia-Yi City, particularly near the Western Foothills, where several active faults have been identified, for example the Chuko and Meishan faults (Fig. 1). Most of the focal depths are located between 5 and $15 \mathrm{~km}$ (Fig. 2). It is also very interesting to see that the upper boundary of the clustering background seismicity (M $>2.0$ ) is approximately dipped to the west, delineated by a red-line in Fig. 1. Surprisingly, the seismicity boundary is dipping to the opposite direction of the decollement beneath the western part of Taiwan (Suppe 1980). In addition to the many micro-earthquakes, some large earthquakes have occurred around the Chia-Yi area, such as the 1906 M 7.1 Meishan earthquake (Omori 1907), the 1998 M 6.8 Rueyli 
earthquake (Wu et al. 2003), and one of the largest Chi-Chi M 6.4 aftershocks (Lin and Ando 2004).

\subsection{Multiple S Waves}

It is interesting to see that multiple $\mathrm{S}$ waves were generated by two local earthquakes (M 4.1 and M 5.0) (Table 1) and clearly recorded at the CHN7 seismic station (Fig. 3). The locations of both earthquakes were well detected by the Central Weather Bureau Seismic Network (CWBSN), which is composed of more than 80 seismic stations for covering the whole Taiwan area (Shin et al. 2000). The focal depths of both earthquakes were 19.6 and $18.3 \mathrm{~km}$, respectively. The epicentral difference between the two earthquakes was only about $2 \mathrm{~km}$. In other words, both earthquakes were located very close to each other. In addition to both the direct $\mathrm{P}$ and $\mathrm{S}$ waves, the velocity seismograms recorded at Station CHN7 showed significant repeated S waves (SS and SSS) in both horizontal components. The arrival times of the three $\mathrm{S}$ waves were approximately $66.9,72.6$, and $78.0 \mathrm{~s}$, shown in Fig. 3a. The arrival-time difference between S and SS was $\sim 5.7 \mathrm{~s}$ and the difference between SS and SSS was $\sim 5.4 \mathrm{~s}$. The epicentral distance to Station CHN7 was $\sim 30 \mathrm{~km}$. Similar observations were also found for Event 2 in Fig. 3b. The arrival times of the three $\mathrm{S}$ waves were around 57.8, 63.6, and $69.1 \mathrm{~s}$. The arrival-time difference between $\mathrm{S}$ and SS was $\sim 5.8 \mathrm{~s}$ and the difference between SS and SSS was $\sim 5.5 \mathrm{~s}$.

As a matter of fact, such a multiple $\mathrm{S}$ waves phenomenon is often observed in the Chia-Yi area. For example, most recently, multiple $\mathrm{S}$ waves were generated by Event 3 (Table 1) and clearly detected again at Station CHN7 on 20 March 2018 (Fig. 4). Besides, we have carefully checked all earthquakes nearby the two earthquakes demonstrated above and recorded at Station CHN7. The criteria for selected earthquakes are (1) magnitudes $>4.0$, (2) depth $>10 \mathrm{~km}$, and (3) located within the area $\left(23.2-23.4^{\circ} \mathrm{N} ; 120.4-120.6^{\circ} \mathrm{E}\right)$ in the period between 1990 and 2016. In total, we examined more than 10 earthquakes and then found that the phenomena of multiple $\mathrm{S}$ waves were repeatedly identified at Station CHN7 (see the attached figures).

\subsection{Converted Waves}

In addition to the multiple $\mathrm{S}$ waves, careful examination of the velocity seismograms, in Fig. 3, shows some con- verted waves arriving between the $\operatorname{direct} \mathrm{P}$ and $\mathrm{S}$ waves. It is clear that the direct $\mathrm{P}$ wave arrived around $61.4 \mathrm{~s}$ for the vertical component while the $\mathrm{S}$ wave was observed at around $66.9 \mathrm{~s}$ for both horizontal components (Fig. 3a). Some seismic energy may have been observed at around $63.5 \mathrm{~s}$ for both horizontal components, which might be due to waves converting from $\mathrm{P}$ to $\mathrm{S}(\mathrm{P}-\mathrm{S})$ due to the polarization of the horizontal component. The arrival difference between the $\mathrm{P}$ and converted waves was $\sim 2.1 \mathrm{~s}$ and the difference between the $\mathrm{S}$ and converted waves was $\sim 3.4 \mathrm{~s}$. Similar features were repeatedly observed in Fig. 3b. The direct $\mathrm{P}$ wave arrived around $52.4 \mathrm{~s}$ on the vertical component while the $\mathrm{S}$ wave was observed around $57.8 \mathrm{~s}$ on both horizontal components (Fig. 3b). The seismic energy of the possibly converted P to $\mathrm{S}$ waves (P-S) was identified around $54.5 \mathrm{~s}$ for both horizontal components. The arrival difference between the $\mathrm{P}$ and $\mathrm{P}-\mathrm{S}$ waves was $\sim 2.1 \mathrm{~s}$ and the difference between the P-S and $\mathrm{S}$ waves was $\sim 3.3 \mathrm{~s}$.

In addition to Station CHN7, the converted waves (P$S)$ were unambiguously identified by another seismic station (Station CHY), located near the epicenter with a distance of $\sim 12 \mathrm{~km}$ (Fig. 5). For instance, the direct $\mathrm{P}$ and $\mathrm{S}$ waves arrived around 59.1 and $62.5 \mathrm{~s}$ in Fig. 5a. The converted waves (P-S) shown on both the horizontal components arrived around $60.7 \mathrm{~s}$. Thus, the arrival difference between the $\mathrm{P}$ and P-S waves was $\sim 1.6 \mathrm{~s}$ and the difference between the $\mathrm{S}$ and $\mathrm{P}-\mathrm{S}$ waves was $\sim 1.8 \mathrm{~s}$. Extremely similar results for the P-S waves were unambiguously found in Fig. 5b.

\section{TRAVEL-TIME SIMULATION}

In order to examine the possible ray-paths to explain the observed multiple $\mathrm{S}$ waves and converted waves (P-S), we have employed a well-developed software, MacRay (Luetgert 1992), to calculate the traveling times and ray-paths by assuming a simplified 2-D velocity model according to some of the previous studies (i.e., Chen et al. 1994; Wen and Chen 2004; Wu et al. 2008). The MacRay is an open software from the USGS web-site (https://earthquake.usgs.gov/ research/software/), which is being able to model the full range of simple to complex ray-paths such as the directed, reflected, refracted and converted wave. Since the Chia-Yi area is largely covered by thick sedimentary rocks (Ho 1988; Lin et al. 2009; Wu and Huang 2013), the $\mathrm{P}$ wave velocity was $4.5 \mathrm{~km} \mathrm{~s}^{-1}$ on the surface and gradually increased to

Table 1. Earthquake parameters (Provided by Central Weather Bureau).

\begin{tabular}{ccccccc}
\hline Earthquake & Longitude (Deg.) & Latitude (Deg.) & Depth $(\mathbf{k m})$ & Magnitude $\left(\mathbf{M}_{\mathbf{L}}\right)$ & YYYY/MM/DD & HH/Min \\
\hline Event 1 & $120.53 \mathrm{E}$ & $23.41 \mathrm{~N}$ & 19.6 & 4.1 & $2017 / 05 / 24$ & $09 / 48$ \\
Event 2 & $120.53 \mathrm{E}$ & $23.43 \mathrm{~N}$ & 18.3 & 5.0 & $2017 / 05 / 24$ & $13 / 10$ \\
Event 3 & $120.54 \mathrm{E}$ & $23.31 \mathrm{~N}$ & 23.31 & 5.2 & $2018 / 03 / 20$ & $17 / 22$ \\
\hline
\end{tabular}



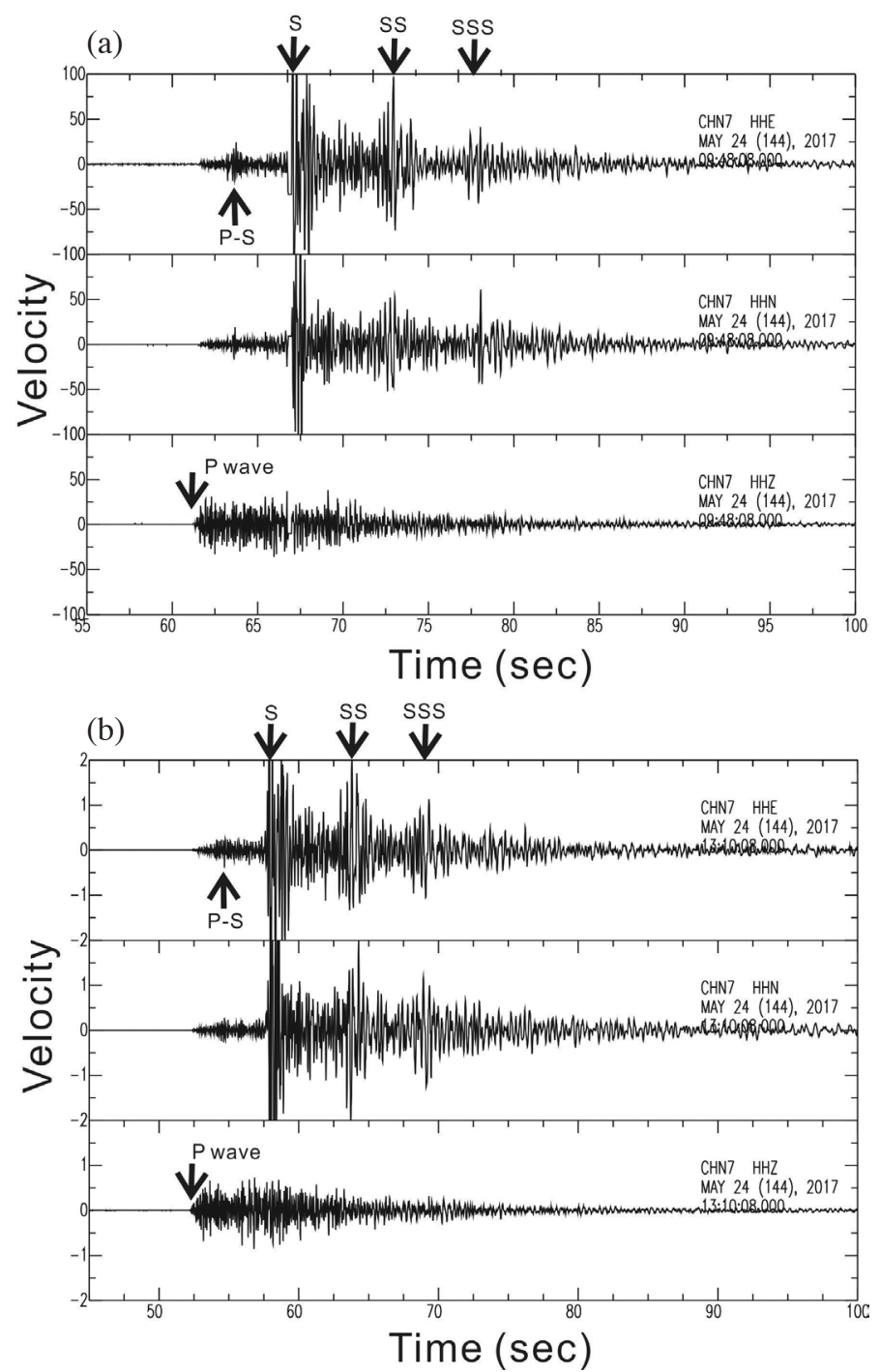

Fig. 3. Velocity seismograms generated by (a) Event 1 and (b) Event 2 at Table 1, recorded at Station CHN7 in the Chia-Yi area. In addition to direct $\mathrm{P}$ and $\mathrm{S}$ waves, the arrivals of multiple S waves are marked by SS and SSS and the P converted S waves are identified by P-S.

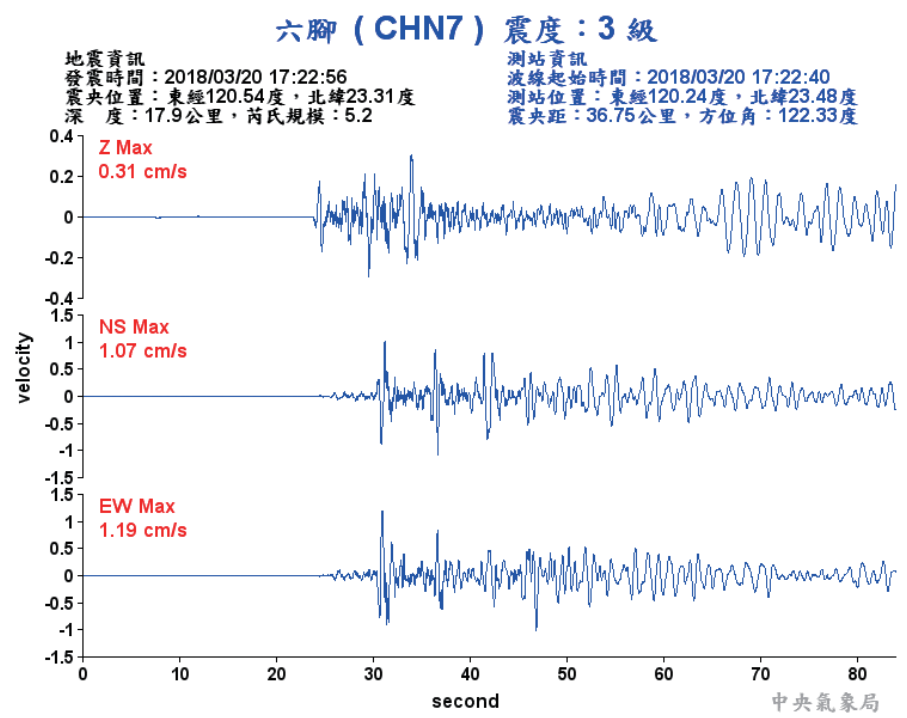

Fig. 4. Velocity seismograms recorded at Station CHN7 in the Chia-Yi area (provided by Central Weather Bureau, https://www.cwb.gov.tw/). 

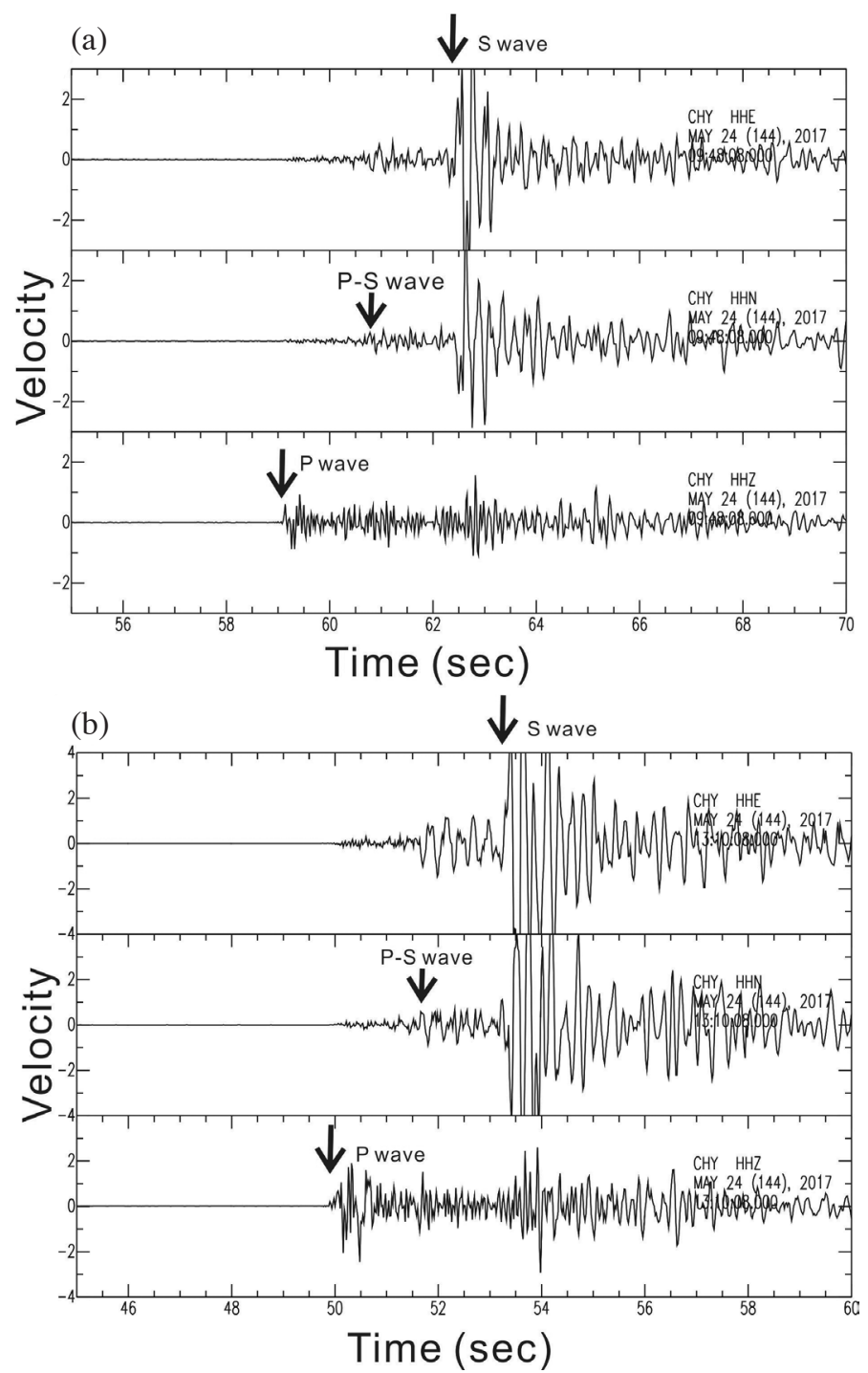

Fig. 5. Velocity seismograms generated by (a) Event 1 and (b) Event 2, recorded at CHY station. In addition to the P and S waves, the wave converted from $\mathrm{P}$ to $\mathrm{S}$ wave is identified by $\mathrm{P}-\mathrm{S}$.

$5.4 \mathrm{~km} \mathrm{~s}^{-1}$ at depths of $\sim 7 \mathrm{~km}$ (Fig. 6). By assumed a major boundary of $\sim 7 \mathrm{~km}$, the velocity below the depth of $7 \mathrm{~km}$ increased from 6.0 to $6.6 \mathrm{~km} \mathrm{~s}^{-1}$ at the lower crust. The $\mathrm{S}$ wave velocities are given by an assumed velocity ratio, between the $\mathrm{P}$ and $\mathrm{S}$ waves, of 1.73 . As a result, a variety of forward modeling calculations have been conducted to calculate the best model to fit the multiple $\mathrm{S}$ waves and the converted waves observed in the Chia-Yi area of western Taiwan.

At first, a 2-dimensional velocity structure in the crust has been constructed according to the geometry of both the earthquake location and the seismic station (Lin 2005, 2009). The source depth of the ray-tracing simulation is fixed at 19 $\mathrm{km}$ based on the focal depth of both local earthquakes (Fig. 1 and Table 1). The seismic station (CHN7) is set at the epicentral distance of around $30 \mathrm{~km}$ (Fig. 7). Although we instinctively started by trying a horizontal boundary in the upper crust, the results do not match the arrival time dif- ferences between the multiple $\mathrm{S}$ waves. In particular, the arrival-time difference between $\mathrm{S}$ and $\mathrm{SS}(5.7-5.8 \mathrm{~s})$, greater than that between SS and SSS (5.4 - 5.5 s), is difficult to model by considering any horizontal boundary. Instead, a boundary dipping toward the west is established. After a variety of forward calculations were attempted to find a suitable model, a final result is obtained (Fig. 7). The major boundary, dipping angle of $\sim 10$ degrees with a small uncertainty ( $<1$ degree), provides the best fit for the observations of the S, SS, and SSS arrivals. In general, the arrival times of the multiple $\mathrm{S}$ waves recorded at Station CHN7 were well modelled at the epicenter distance of $\sim 30 \mathrm{~km}$ (Fig. 8).

In addition to fitting the multiple $S$ waves, the final velocity structure shown in Fig. 6 consistently provided an acceptable result to explain the $\mathrm{P}$ waves converted into $\mathrm{S}$ waves (P-S) recorded at Station CHN7 in Fig. 3 and Station $\mathrm{CHY}$ in Fig. 4. A forward modeling of the $\mathrm{P}$ waves 


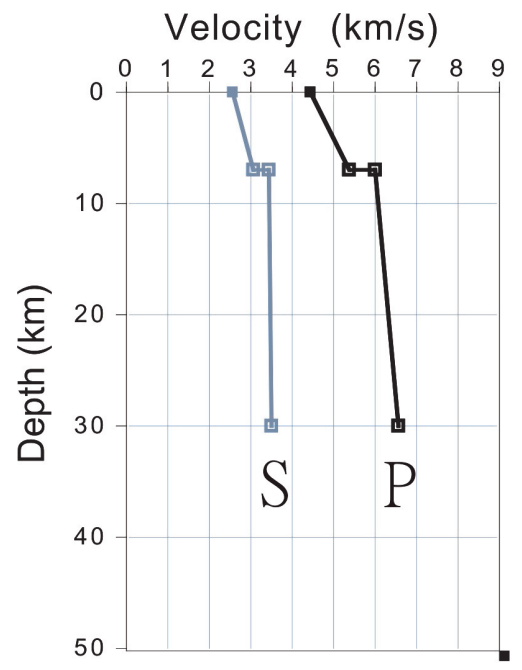

Fig. 6. Simplified 1-D crustal velocity structures beneath the Chia-Yi area (modified from Chen et al. 1994).

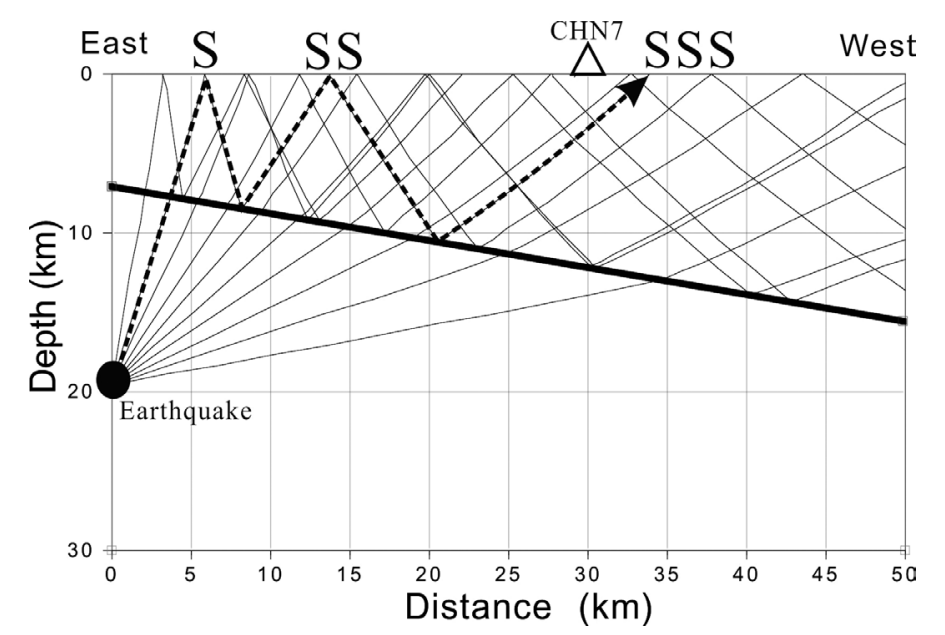

Fig. 7. Ray-tracing for direct $\mathrm{S}$ wave and the multiple reflections of $1^{\text {st }}(\mathrm{SS})$ and $2^{\text {nd }}(\mathrm{SSS})$.

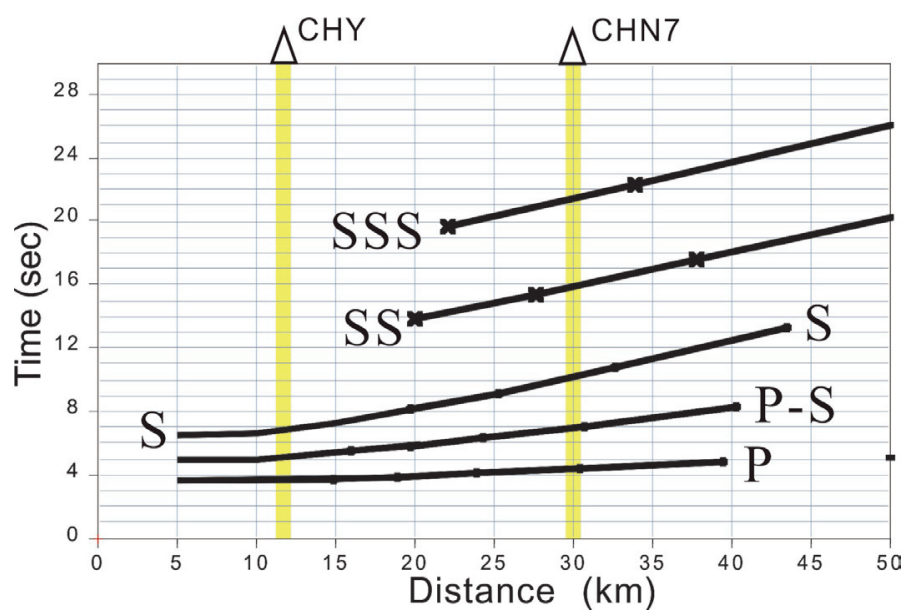

Fig. 8. Travel-time curves for different rays, including P (direct P), S (direct S), P-S (P converted into S at the boundary), SS (S waves reflected once at the boundary), and SSS (S waves reflected twice at the boundary). 
converting into $\mathrm{S}$ waves on the dipping boundary is shown in Fig. 9. The arrival times of the simulated results are generally consistent with the $\mathrm{P}, \mathrm{P}-\mathrm{S}$, and $\mathrm{S}$ waves recorded at Stations CHY and CHN7 (Fig. 8). For instance, for Station CHN7, at the epicentral distance of $\sim 30 \mathrm{~km}$, the arrival difference between the $\mathrm{P}$ and $\mathrm{P}-\mathrm{S}$ was $\sim 2.1$ and $\sim 3.3 \mathrm{~s}$ between the P-S and $\mathrm{S}$ waves. For Station CHY at the epicenter distance of $\sim 12 \mathrm{~km}$, the arrival difference between the $\mathrm{P}$ and $\mathrm{P}-\mathrm{S}$ waves was $\sim 1.6 \mathrm{~s}$ and the difference between the P-S and $\mathrm{S}$ waves was $\sim 1.8 \mathrm{~s}$.

\section{RESULTS AND DISCUSSION}

Based on simulation results of both the multiple $S$ waves ( $\mathrm{S}, \mathrm{SS}$, and SSS) and the $\mathrm{P}$ converted $\mathrm{S}$ waves (P-S), there is a major velocity boundary dipping to the west beneath the Chia-Yi area of western Taiwan. Although those seismic waves were only observed at two seismic stations (CHN7 and $\mathrm{CHY}$ ), a simplified subsurface structure along the westeast profile was accurately constrained by unambiguous observations (Figs. 3, 4, and 5). A significant seismic boundary dipping of $\sim 10$ degree to the west is required between Stations $\mathrm{CHY}$ and $\mathrm{CHN} 7$ to match the multiple $\mathrm{S}$ wave and the $\mathrm{P}$ converted $\mathrm{S}$ wave observations. The depth of the boundary is $\sim 7 \mathrm{~km}$ beneath the Western Foothills and then gradually increases to $\sim 12 \mathrm{~km}$ beneath the Coastal Plain.

The westward dipping boundary observed from the clear multiple $\mathrm{S}$ waves and the converted waves is surprisingly consistent with the seismicity boundary beneath the Chia-Yi area (Fig. 1). The background seismicity was clustered below the seismic boundary dipped to the west, while there were extremely limited earthquakes occurring shallower than the boundary. Also, larger earthquakes often occur around the mid-crust beneath the Chia-Yi area. In short, the consistent features of the seismicity pattern and the velocity structures strongly suggest that there is a major boundary in the upper crust and that, potentially, large earthquakes might be taking place in and just below the boundary. Certainly, a more detailed geometry of this boundary must be obtained by deploying dense seismic arrays in the future.

Such a west-dipping boundary was not reported, even although some other similar boundaries were observed beneath the Chai-Yi area of western Taiwan (Wen and Chen 2004; Chen et al. 2008). The major difference between the west-dipping boundary obtained here and the previous results is the dipping angle and the spatial location. The westdipping boundary of $\sim 35$ degrees was revealed from the seismic tomography and seismicity (Wen and Chen 2004). Similar results were also obtained by Chen et al. (2008), who suggested the west-dipping boundary was a back-thrust faulting. However, the dipping angle obtained here is only about 10 degrees. Also, the exact locations between the west-dipping boundary obtained here and the previous results is not well matched. Thus, the west-dipping boundary obtained in this study is a new observation.

It is obvious that the major seismic boundary detected from the earthquake data herein is not the well-known decollement in the western Taiwan area. Firstly, the boundary with depths ranging from 7 to $12 \mathrm{~km}$ in the study area is distinguishable from the decollement, occurring at depths of $\sim 5 \mathrm{~km}$ in the western Taiwan area. The depth of this boundary is about $7 \mathrm{~km}$ beneath the Western Foothills, while this boundary gradually descends to $\sim 12 \mathrm{~km}$ beneath the Coastal Plain. Obviously, this boundary is deeper than the decollement proposed earlier. Secondly, the deeper boundary found from both the multiple $\mathrm{S}$ waves and the converted waves in this study is dipping to the opposite direction of the decollement. In other words, the decollement at the uppermost crust is dipping to the east, while the deeper boundary is dipping to the west. As a matter of fact, the seismic data obtained herein does not show any significant boundary

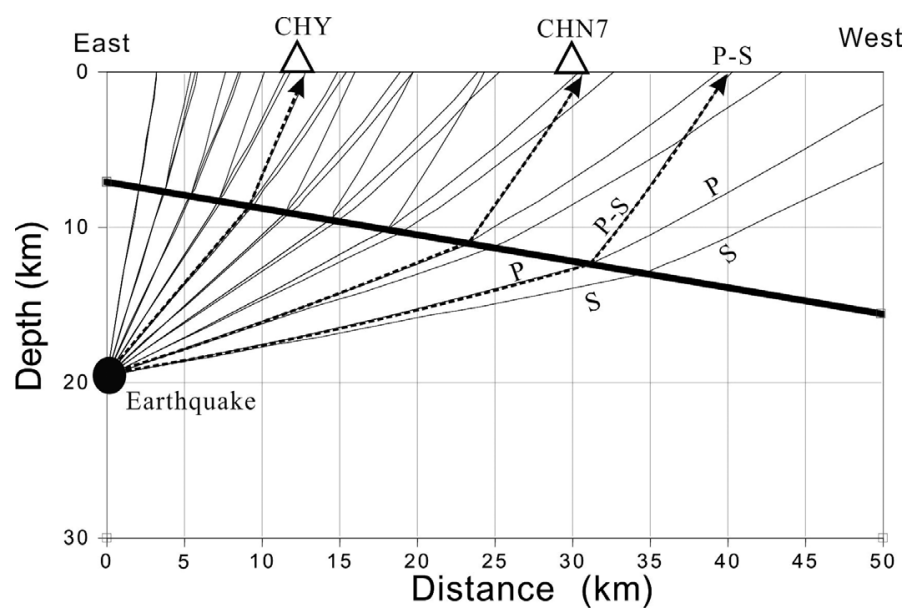

Fig. 9. Ray-tracing for direct S wave and P-S (P converted into S at the boundary). 
near the well-known decollement. Instead, another boundary deeper than the decollement was clearly detected. This observation suggests that the decollement might be a kind of geological boundary whereas the deeper one observed herein is a seismic boundary. Thus, this velocity boundary, instead of the decollement boundary, might be considered as the primary seismogenic boundary.

\section{CONCLUSION}

We have carefully examined the waveforms generated by more than two earthquakes recorded at seismic stations in the Chia-Yi area, to verify the existence of the decollement or any other boundary beneath the Coastal Plain of western Taiwan. It is interesting to see the unambiguous multiple $\mathrm{S}$ waves and the converted phases from $\mathrm{P}$ to $\mathrm{S}$ waves in the upper crust. Careful comparison between the observations and the calculated results of both the travel-time and the ray-path indicates that there is a major boundary in the upper crust. This boundary is dipping to the west and the depth ranges from $\sim 7 \mathrm{~km}$ beneath the Western Foothills to $\sim 12 \mathrm{~km}$ beneath the Coastal Plain. The dipping angle is about 10 degrees. It is also very interesting to note that this boundary is not only a velocity boundary but is also consistent with the seismicity boundary. In other words, background earthquakes are limited to depths below this boundary while there are only a few earthquakes shallower than this boundary. Obviously, this major velocity boundary is deeper than the decollement that might be a geological boundary in western Taiwan. As a result, the westward dipping boundary obtained in this study is more suitable than the eastward dipping decollement to be the seismogenic boundary in the Chia-Yi area of western Taiwan.

Acknowledgements We would like to acknowledge the financial support from the Ministry of Science and Technology in Taiwan. The seismic data provided by the Central Weather Bureau and the Institute of Earth Sciences, Academia Sinica are also appreciated. Thanks are also extended to two anonymous reviewers for providing valuable comments and suggestions.

\section{REFERENCES}

Byrne, T., Y.-C. Chan. R.-J. Rau, C.-Y. Lu, Y.-H. Lee, and Y.-J. Wang, 2011: The Arc-Continent Collision in Taiwan. In: Brown, D. and P. D. Ryan (Eds.), Arc-Continent Collision, Springer, Berlin, Heidelberg, 213-245, doi: 10.1007/978-3-540-88558-0_8. [Link]

Chen, C. H., W. H. Wang, and Y. H. Yen, 1994: 3-D velocity structure in Taiwan: A tectonic implication of continent-arc collision (abstract). Eos, Trans., AGU, 75, 645 .

Chen, Y. G., Y. T. Kuo, Y. M. Wu, H. L. Chen, C. H. Chang,
R. Y. Chen, P. W. Lo, K. E. Ching, and J. C. Lee, 2008: New seismogenic source and deep structures revealed by the 1999 Chia-yi earthquake sequence in southwestern Taiwan. Geophys. J. Int., 172, 1049-1054, doi: 10.1111/j.1365-246x.2007.03686.x. [Link]

Ho, C.-S., 1988: An Introduction to the Geology of Taiwan: Explanatory Text of the Geologic Map of Taiwan, Second Ed., Ministry of Economic Affairs, Taipei, Taiwan, $192 \mathrm{pp}$.

Lin, C.-H., 2000: Thermal modeling of continental subduction and exhumation constrained by heat flow and seismicity in Taiwan. Tectonophysics, 324, 189-201, doi: 10.1016/s0040-1951(00)00117-7. [Link]

Lin, C.-H., 2001: The 1999 Taiwan earthquake: A proposed stress-focusing, heel-shaped model. Bull. Seismol.Soc. Am., 91, 1053-1061, doi: 10.1785/0120000723. [Link]

Lin, C.-H., 2002: Active continental subduction and crustal exhumation: The Taiwan orogeny. Terr. Nova, 14,281287, doi: 10.1046/j.1365-3121.2002.00421.x. [Link]

Lin, C.-H., 2005: Identification of mantle reflections from a dense linear seismic array: Tectonic implications to the Taiwan orogeny. Geophys. Res. Lett., 32, L06315, doi: 10.1029/2004g1021814. [Link]

Lin, C.-H., 2009: Compelling evidence of an aseismic slab beneath central Taiwan from a dense linear seismic array. Tectonophysics, 466, 205-212, doi: 10.1016/j. tecto.2007.11.029. [Link]

Lin, C.-H. and M. Ando, 2004: Seismological evidence of simultaneous mountain-building and crust-thickening from the 1999 Taiwan Chi-Chi earthquake ( $\mathrm{Mw}=7.6)$. Earth Planets Space, 56, 163-167, doi: 10.1186/ bf03353400. [Link]

Lin, C.-M., T.-M. Chang, Y.-C. Huang, H.-J. Chiang, C.H. Kuo, and K.-L. Wen, 2009: Shallow S-wave velocity structures in the western coastal plain of Taiwan. Terr. Atmos. Ocean. Sci., 20, 299-308, doi: 10.3319/ TAO.2007.12.10.01(T). [Link]

Lin, Q.-W., S.-T. Lu, T.-S. Shih, W.-H. Lin, Y.-C. Liu, and P.-T. Chen, 2008: Active faults of central Taiwan: Explanatory text for the strip maps of active faults scale 1:25,000. Spec. Publ. Cent. Geol. Surv., 21, 1-148.

Luetgert, J. H., 1992: MacRay; Interactive two-dimensional seismic raytracing for the Macintosh. Open-File Report 92-356, U.S. Geological Survey, 45 pp.

Malavieille, J. and G. Trullenque, 2009: Consequences of continental subduction on forearc basin and accretionary wedge deformation in SE Taiwan: Insights from analogue modeling. Tectonophysics, 466, 377-394, doi: 10.1016/j.tecto.2007.11.016. [Link]

Malavieille, J., S. E. Lallemand, S. Dominguez, A. Deschamps, C.-Y. Lu, C.-S. Liu, P. Schnuerle, J. Angelier, J. Y. Collot, B. Deffontaines, M. Fournier, S. K. Hsu, J. P. Le Formal, S. Y. Liu, J. C. Sibuet, N. Thareau, and F. Wang, 2002: Arc-continent collision in Taiwan: New 
Marine observations and tectonic evolution. In: Byrne, T. B. and C.-S. Liu (Eds.), Geology and Geophysics of an Arc-Continent Collision, Taiwan, Geological Society of America Special Paper 358, 187-211, doi: 10.1130/0-8137-2358-2.187. [Link]

Omori, F., 1907: Preliminary Note on the Formosa Earthquake of March 17, 1906. Bulletin of the Imperial Earthquake Investigation Committee, 1, 53-69.

Shin, T. C., K. W. Kuo, W. H. K. Lee, T. L. Teng, and Y. B. Tsai, 2000: A preliminary report on the 1999 Chi-Chi (Taiwan) earthquake. Seismol. Res. Lett., 71, 24-30, doi: 10.1785/gssrl.71.1.24. [Link]

Suppe, J., 1980: Imbricated structure of western Foothills belt, southcentral Taiwan. Petrol. Geol. Taiwan, 17, $1-16$.

Suppe, J., 1981: Mechanics of mountain building and metamorphism in Taiwan. Mem. Geol. Soc. China, 4, 67-89.

Teng, L. S., 1996: Extensional collapse of the northern Taiwan mountain belt. Geology, 24, 949-952, doi: 10.113 0/0091-7613(1996)024<0949:ecotnt>2.3.co;2. [Link]

Wen, S. and C. H. Chen, 2004: 3-D velocity structure beneath the Chia-Nan area, Taiwan. Terr. Atmos. Ocean. Sci.,15,239-259, doi: 10.3319/TAO.2004.15.2.239(T). [Link]

Wu, C. F. and H. C. Huang, 2013: Near-surface shearwave velocity structure of the Chiayi area, Taiwan. Bull. Seismol. Soc. Am., 103, 1154-1164, doi: 10.1785/0120110245. [Link]

Wu, Y.-M., C.-H. Chang, N.-C. Hsiao, and F.-T. Wu, 2003: Relocation of the 1998 Rueyli, Taiwan, earthquake sequence using three-dimensions velocity structure with stations corrections. Terr. Atmos. Ocean. Sci., 14, 421430, doi: 10.3319/TAO.2003.14.4.421(T). [Link]

Wu, Y.-M., C.-H. Chang, L. Zhao, T.-L. Teng, and M. Nakamura, 2008: A comprehensive relocation of earthquakes in Taiwan from 1991 to 2005. Bull. Seismol. Soc. Am., 98, 1471-1481, doi: 10.1785/0120070166. [Link]

\section{APPENDIX}

Appendix figures for showing more cased of the multiple S waves recorded at Station CHN7 in the Chia-Yi area, Taiwan.
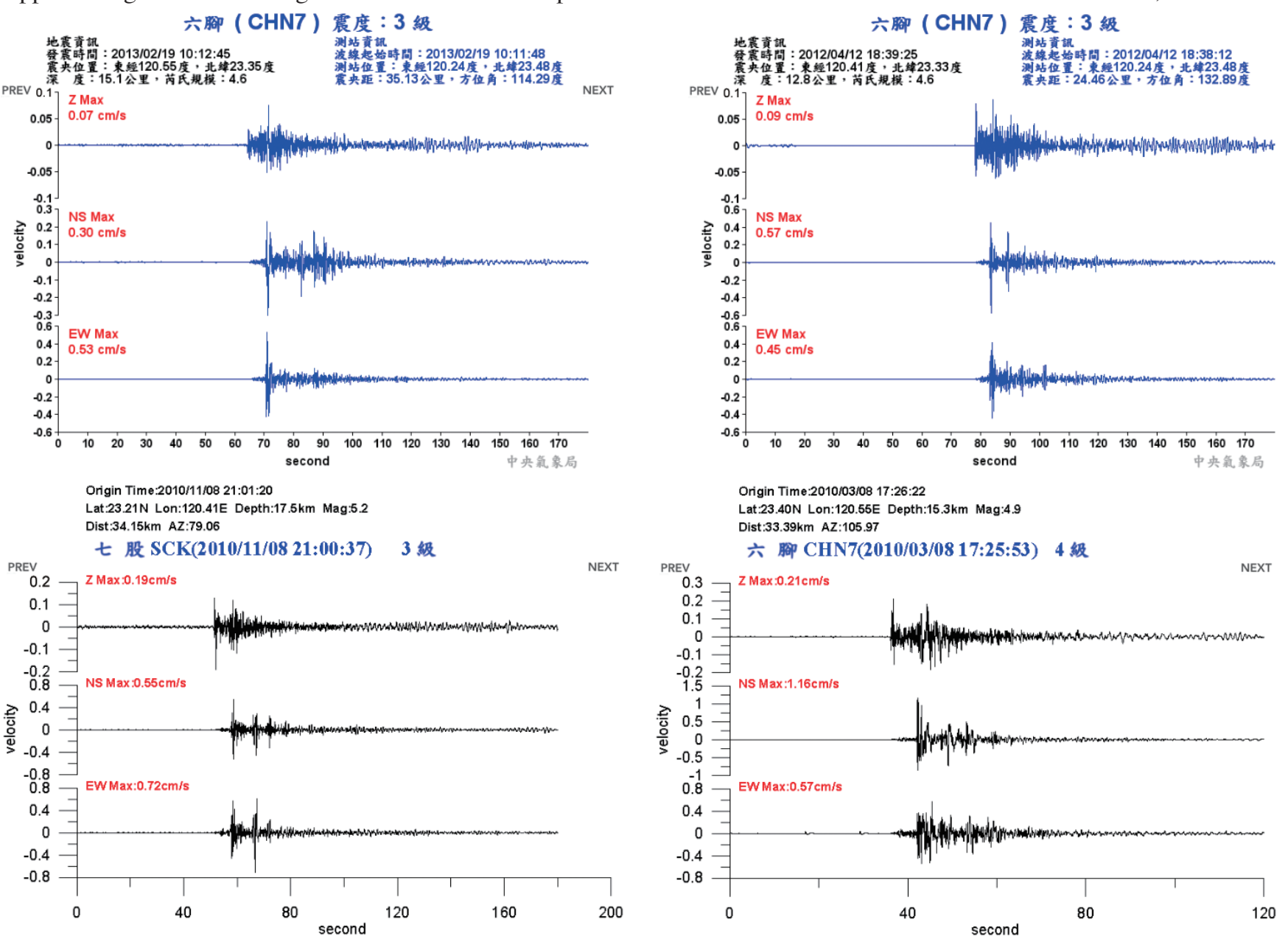